\title{
ChemElectroChem
}

Supporting Information

\section{Boosting Oxygen and Peroxide Reduction Reactions on PdCu Intermetallic Cubes}

Qingfeng Zhang, Fan Li, Lina Lin, Jiaheng Peng, Wencong Zhang, Wenlong Chen, Qian Xiang, Fenglei Shi, Wen Shang, Peng Tao, Chengyi Song, Rong Huang, ${ }^{*}$ Hong Zhu, Tao Deng, and Jianbo Wu* 


\section{Supporting Information}

\section{Phase transfer of Pd cubes}

In a standard procedure, $8 \mathrm{~mL}$ of ethanol solution containing the Pd cubes, $5 \mathrm{~mL}$ of OLA and $3 \mathrm{~mL}$ of toluene were mixed in a $20 \mathrm{~mL}$ glass vial. After the reaction kept at $80^{\circ} \mathrm{C}$ over-night, the product was washed with ethanol by centrifugation and then redispersed in chloroform for further characterization.

\section{Preparation of Carbon-Supported PdCu Catalysts Carbon}

In a standard preparation, Carbon black (Vulcan XC-72) particles were dispersed in chloroform and sonicated for $1 \mathrm{~h}$. A predetermined amount of $\mathrm{PdCu}$ nanoparticles (20\% loading) was then added to this dispersion. This mixture was sonicated for additional $30 \mathrm{~min}$ and stirred overnight. The resultant solids were precipitated out by centrifugation at $5000 \mathrm{rpm}$ for $5 \mathrm{~min}$ and dried under a stream of argon gas.

The solid product was re-dispersed in $20 \mathrm{ml} \mathrm{n}$-butylamine and stirred for 3 days to deoil before centrifuged at a rate of $5000 \mathrm{rpm}$ for $5 \mathrm{~min}$. The precipitate was redispersed in $10 \mathrm{~mL}$ methanol by sonication for $15 \mathrm{~min}$, followed by centrifugation at $8000 \mathrm{rpm}$ for 3 times. The final samples were dried under a stream of argon gas.

\section{Characterizations}

XRD patterns were recorded in a scan range of $10-90^{\circ}$ at a scan rate of $5.0^{\circ} \mathrm{min}^{-1}$ by using X-Ray diffraction (Rigaku, Ultima IV) with $\mathrm{Cu} \mathrm{K \alpha}$ radiation $(\lambda=1.54178 \AA$ ). The TEM was carried out on a JEM-2100F field emission electron microscope at an acceleration voltage of $200 \mathrm{kV}$. The HRTEM and the corresponding EDS mapping analyses were performed on a JEOL JEM-ARM300F with a spherical aberration corrector.

The elemental ratio of $\mathrm{PdCu}$ were measured on ICP spectrometer on a 6300 instrument (Thermo Electron Corp.).

\section{Electrochemical measurement}

The three-electrode cell equipped with the CHI760E electrochemical analyzer (CH Instrument, Shanghai) was used to measure the electrochemical performance of catalysts.

\section{Oxygen reduction reaction $(\mathrm{ORR})$}

The glassy-carbon rotating disk electrode (RDE, area: $\sim 0.196 \mathrm{~cm}^{2}$ ), a $4 \mathrm{~cm}$ platinum wire and the Reversible hydrogen electrode (calibrated before test) were utilized as the working, counter, and reference electrodes, respectively.

The loading of the $\mathrm{PdCu}$ on the carbon black was confirmed by the TGA instrument (TG550). $5 \mathrm{mg}$ of $\mathrm{PdCu}$ catalysts, $4 \mathrm{ml}$ of deionized water, $1 \mathrm{ml}$ of isopropanol and $25 \mu \mathrm{L}$ of $5 \%$ Nafion solution were mixed and sonicated for $15 \mathrm{~min}$. $48 \mu \mathrm{L}$ of the ink (the loading amount of $\mathrm{Pd}$ is $6 \mu \mathrm{g}$ ) was added on the RDE and dried in the air naturally. For other catalysts ink, the loading amount of noble metal $(\mathrm{Pd} / \mathrm{Pt})$ was kept at $6 \mu \mathrm{g}$. 
Before every electrochemical measurement, the CV measurement was carried in the $0.1 \mathrm{M} \mathrm{KOH}$ to activate the electrode. The $\mathrm{CV}$ curves were recorded from $0.05 \mathrm{~V}$ to $1 \mathrm{~V}$ with the scan rate of $50 \mathrm{mV} / \mathrm{s}$. The electrochemical active surface area (ECSA) of $\mathrm{Pt} / \mathrm{C}$ was calculated by integrating the hydrogen absorption charge on $\mathrm{CV}$ curves. ECSAs of $\mathrm{Pd} / \mathrm{C}$ and $\mathrm{PdCu} / \mathrm{C}$ catalysts were determined by $\mathrm{CO}$ stripping. The working electrode was immersed in the CO-saturated $0.1 \mathrm{M} \mathrm{KOH}$ and held at $0.3 \mathrm{~V}$ for $15 \mathrm{~min}$ before plunged quickly into the Ar-saturated $0.1 \mathrm{M} \mathrm{KOH}$ to run $\mathrm{CV}$ from 0 to $1.2 \mathrm{~V}$ using scan rate of $50 \mathrm{mV} / \mathrm{s}$. The ECSAs were calculated by subtracting the background charge (the second CV), assuming a charge density of $420 \mu \mathrm{C} \mathrm{cm}{ }^{-2}$.

ORR LSV curves were obtained in the $\mathrm{O}_{2}$-saturated $0.1 \mathrm{M} \mathrm{KOH}$ at the rotating speed of $1600 \mathrm{rpm}$. The electrolyte was purged with oxygen for $30 \mathrm{~min}$ before test. The LSV curves were recorded at the scan rate of $10 \mathrm{mV} / \mathrm{s}$ and repeated 20 times to be stable. IR-compensation was used to get the final LSV curves and calculate the kinetic current.

The accelerated stability test (ADT) was carried out between $0.6 \mathrm{~V}$ and $1.0 \mathrm{~V}$ at a scan rate of $100 \mathrm{mV} / \mathrm{s}^{-1}$ for 30000 cycles in Ar-saturated $0.1 \mathrm{M} \mathrm{KOH}$ solution.

\section{Hydrogen peroxide reduction reaction}

The glassy-carbon electrode (GCE, area: $\sim 0.071 \mathrm{~cm}^{2}$ ), a $4 \mathrm{~cm}$ platinum wire and the saturated calomel electrode (SCE) were utilized as the working, counter, and reference electrodes, respectively.

$5 \mathrm{mg}$ of $\mathrm{PdCu}$ catalysts, $2 \mathrm{ml}$ of deionized water, $1 \mathrm{ml}$ of isopropanol and $25 \mu \mathrm{L}$ of $5 \%$ Nafion solution were mixed and sonicated for $15 \mathrm{~min}$ for making the catalyst ink. $10 \mu \mathrm{L}$ of the ink (the loading amount of Pd is $2 \mu \mathrm{g}$ ) was added on the GCE and dried in the air naturally. For other catalysts ink, the loading amount of noble metal $(\mathrm{Pd} / \mathrm{Pt})$ was kept at $2 \mu \mathrm{g}$.

All the measurements were measured in the $15 \mathrm{ml}$ bottle with $10 \mathrm{ml}$ electrolyte. The CV same measurements were used to activate the catalysts in $0.1 \mathrm{M} \mathrm{HClO} 4$.Then the working electrode was switched to $0.1 \mathrm{M}$ PBS $(\mathrm{PH}=7)$ to record $\mathrm{CV}$ curves from 0.5 to $0.7 \mathrm{~V}$ with the scan rate of $50 \mathrm{mV} / \mathrm{s}$. After drop $5 \mu \mathrm{L}$ of $\mathrm{H} 2 \mathrm{O} 2$ solution, $\mathrm{CV}$ curves were recorded with increasing scan rate $(50,75,100,125$ and $150 \mathrm{mV} / \mathrm{s})$. CV curves with increasing $\mathrm{H}_{2} \mathrm{O}_{2}$ concentration $(5,10,15,20,25 \mathrm{mM})$ were recorded at the scan rate of $100 \mathrm{mV} / \mathrm{s}$. All the electrolytes were plunged with argon for $15 \mathrm{~min}$ to make argon saturated in solution before measurements.

\section{Density Functional Theory (DFT) Computational Model and Method}

\section{Analysis}

\section{Methodology}

We carried out the density functional theory (DFT) calculations on the basis of the projector augmented wave (PAW) method ${ }^{[1]}$ by utilizing the Vienna ab initio simulation package (VASP) ${ }^{[2],[3]}$ with the generalized gradient approximation $(\mathrm{GGA})^{[4]}$, the Perdew-Burke-Ernzerhof (PBE) exchange-correlation functional in the treatment of electron-ion interactions and a cutoff energy of $520 \mathrm{eV}$ for a plane wave expansion of 
the wave functions. The $\mathrm{PdCu}(100)$ and (110) slabs were built to represent the cubic and spherical PdCu model on the base of the corresponding HAADF-STEM and HRTEM images. We use a $4 \times 4$ supercell slab with 7 atomic layers for $\mathrm{PdCu}(100)$ slab (Figure S1a), and use a $4 \times 2$ supercell slab with 6 atomic layers for $\mathrm{PdCu}(110)$ slab (Figure S1b), respectively. A Monkhorst-Pack grid of size of $2 \times 2 \times 1$ was used to sample the surface Brillouin zone ${ }^{[5]}$. A vacuum region of $15 \AA$ was added to give converged adsorption energies while the energy convergence criterion is $0.0001 \mathrm{eV} /$ atom for electronic minimization steps. The slabs were shown in Figure S14.

\section{Adsorption Energy Analysis on Oxygen Reduction Reaction}

To clarify the effect of the shape of $\mathrm{PdCu}$ nanoparticles on activity of oxygen reduction reaction, we calculate the adsorption energy of oxygen atom. The detailed calculation method was similar to our previous work ${ }^{[6]}$. And the stable adsorption site and energy were shown in Figure $4 a$ and $4 b$.

\section{Energy Barrier Analysis on $\mathrm{H}_{2} \mathrm{O}_{2}$ Decomposition}

To discuss the shaped enhanced peroxide reduction reaction, we calculated the energy barrier of its rate-determining step, which is as follows,

$$
\mathrm{H}_{2} \mathrm{O}_{2}{ }^{*}+e^{-} \rightarrow \mathrm{OH}^{*}+\mathrm{OH}^{-} \quad(1)^{[7]}
$$

The most stable adsorption energy for $\mathrm{H}_{2} \mathrm{O}_{2}$ were calculated on the surface of $\mathrm{PdCu}(100)$ and (111) slabs while the $\mathrm{H}_{2} \mathrm{O}_{2}$ molecules were allowed to relax. One of $\mathrm{OHs}$, which prefers binding to the surface, was left on the slab surface, while another one, which will combine with $\mathrm{H}+$ to from $\mathrm{H}_{2} \mathrm{O}$, were removed from the slab surface. The calculated results were listed in Figure $4 \mathrm{c}$ and $4 \mathrm{~d}$.

Table S1. Elements content of $\mathrm{PdCu}$ cubes and spheres

\begin{tabular}{lcccc}
\hline \multicolumn{1}{c}{ Sample } & \multicolumn{2}{c}{ Before ADT test } & \multicolumn{2}{c}{ After ADT test } \\
& $\begin{array}{c}\text { Pd\% } \\
\text { Atoms/Mass }\end{array}$ & $\begin{array}{c}\text { Cu\% } \\
\text { Atoms/Mass }\end{array}$ & $\begin{array}{c}\text { Pd\% } \\
\text { Atoms/Mass }\end{array}$ & $\begin{array}{c}\text { Cu\% } \\
\text { Atoms/Mass }\end{array}$ \\
\hline PdCu cubes & $51.5 / 63.8$ & $48.5 / 36.2$ & $57.9 / 70.1$ & $42.1 / 29.9$ \\
PdCu spheres & $55.6 / 67.5$ & $44.4 / 32.5$ & $62.3 / 73.2$ & $37.7 / 26.8$ \\
\hline
\end{tabular}


Table S2. Electrochemical parameters of catalysts before and after ADT

\begin{tabular}{cccc}
\hline Samples & $\mathbf{E C S A}\left(\mathbf{m}^{\mathbf{2}} / \mathbf{g}\right)$ & $\mathbf{i}_{\mathbf{s}}\left(\mathbf{m} \mathbf{A} / \mathbf{c m}_{\mathbf{P d}}^{2}\right)$ & $\mathbf{i}_{\mathbf{m}} \mathbf{( A / \mathbf { m g } _ { \mathbf { P d } } )}$ \\
\hline $\mathrm{PdCu}$ cube/C & 59.4 & 0.422 & 0.251 \\
$\mathrm{PdCu}$ cube/C after ADT & 35.4 & 0.483 & 0.171 \\
$\mathrm{PdCu}$ Sphere/C & 36.6 & 0.145 & 0.054 \\
$\mathrm{PdCu} \mathrm{Sphere/C} \mathrm{after}$ & 17.0 & 0.183 & 0.031 \\
$\mathrm{ADT}$ & & & \\
$\mathrm{Pd} \mathrm{Cube} / \mathrm{C}$ & 43.3 & 0.412 & 0.182 \\
$\mathrm{Pd} \mathrm{Cube/C} \mathrm{after} \mathrm{ADT}$ & 33.3 & 0.306 & 0.101 \\
$\mathrm{Pd} / \mathrm{C}$ & 51.5 & 0.116 & 0.061 \\
$\mathrm{Pd} / \mathrm{C}$ after ADT & 31.9 & 0.122 & 0.039 \\
$\mathrm{Pt} / \mathrm{C}$ & 63.2 & 0.086 & 0.056 \\
$\mathrm{Pt} / \mathrm{C}$ after ADT & 30.3 & 0.069 & 0.021 \\
\hline
\end{tabular}
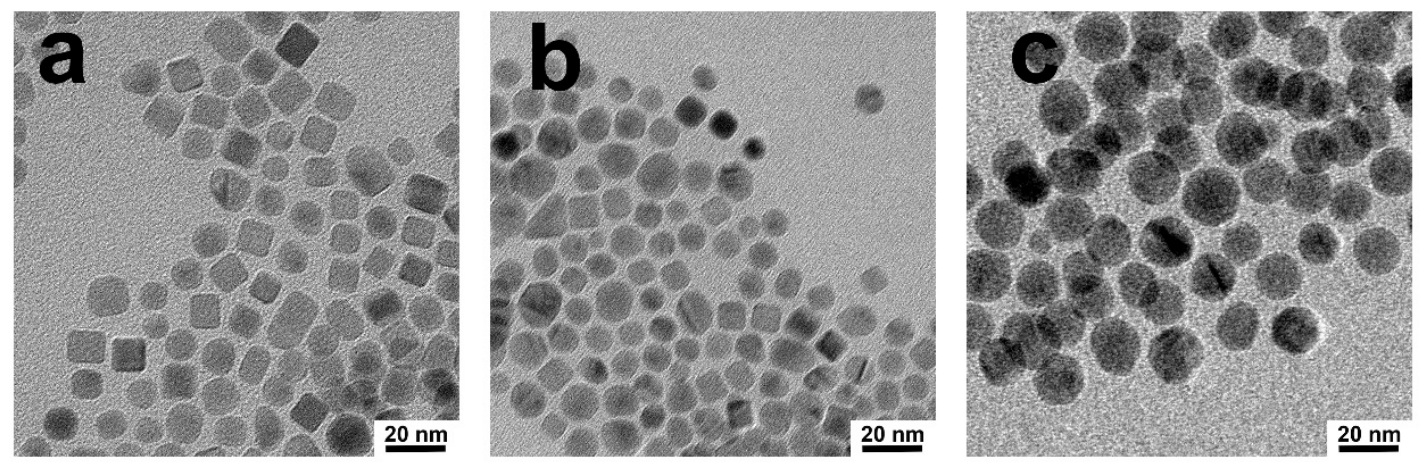

Figure S1. TEM images of $\mathrm{PdCu}$ nanoparticles at different temperature. (a) $180^{\circ} \mathrm{C}$ (b) $200^{\circ} \mathrm{C}$ (c) $220^{\circ} \mathrm{C}$ 


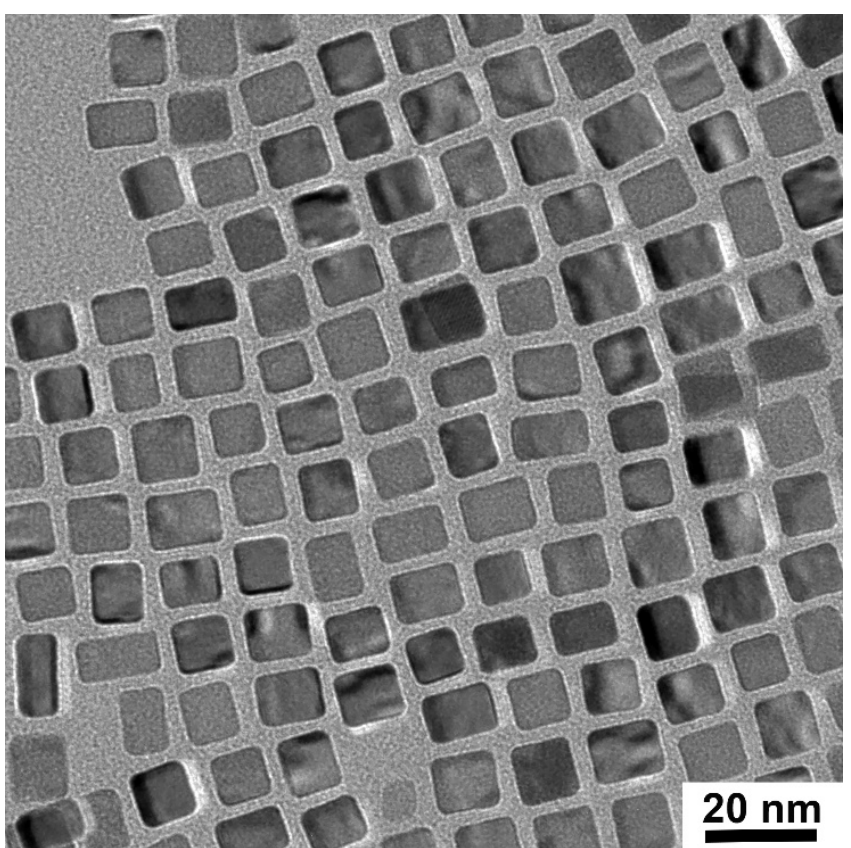

Figure S2. TEM image of Pd Cubes

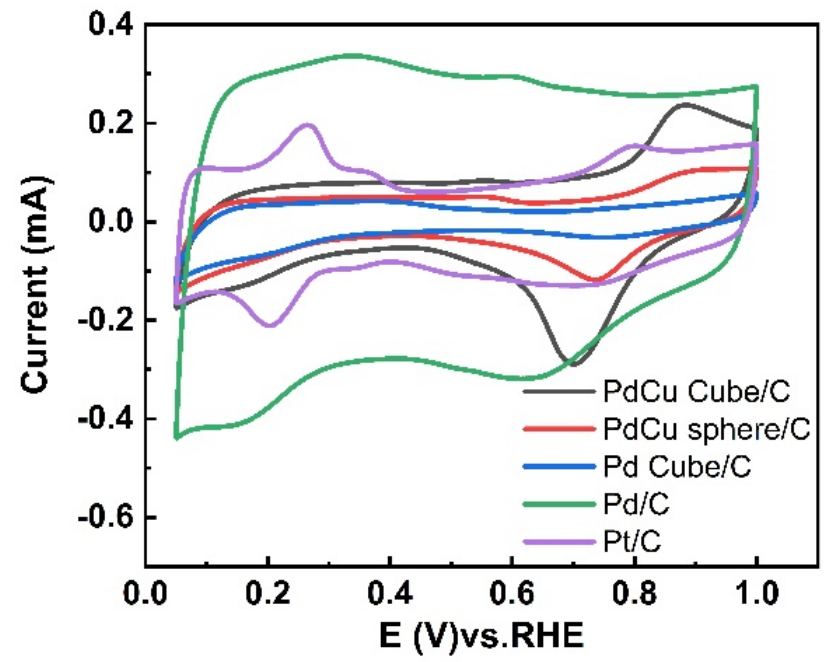

Figure S3. CV curves of the stated catalysts in $0.1 \mathrm{M} \mathrm{KOH}$ 


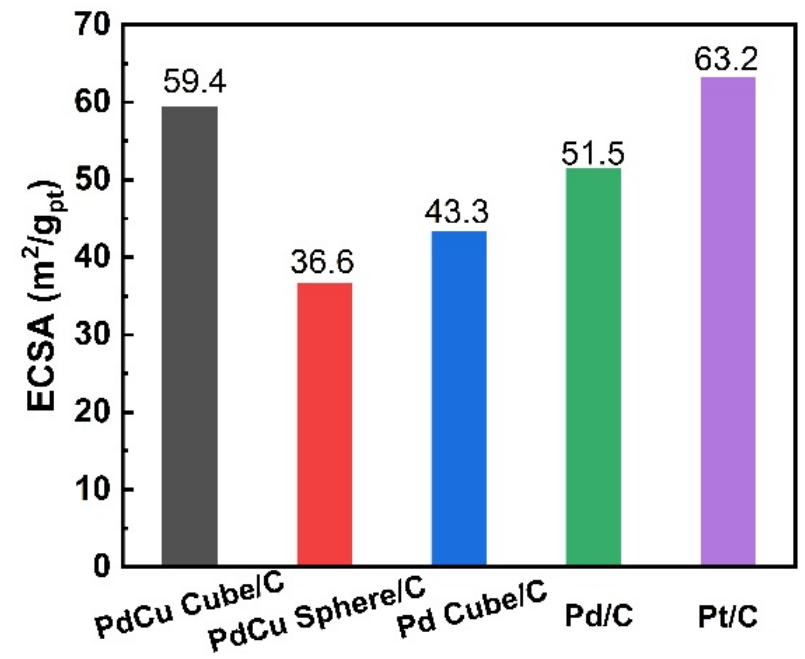

Figure S4. Initial ECSAs of the stated catalysts in $0.1 \mathrm{M} \mathrm{KOH}$

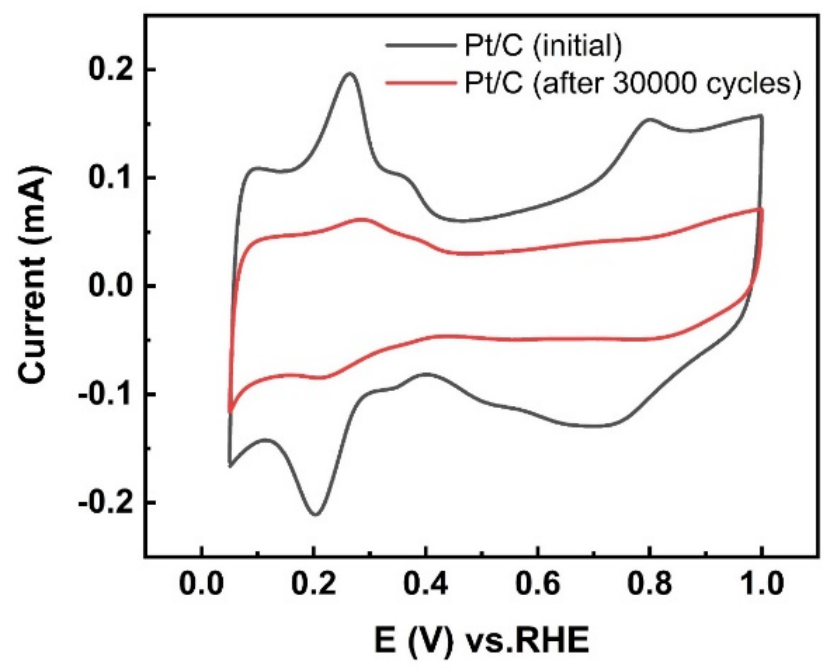

Figure S5. CV curves of the commercial Pt/C before and after 30000 cycles in $0.1 \mathrm{M}$ $\mathrm{KOH}$
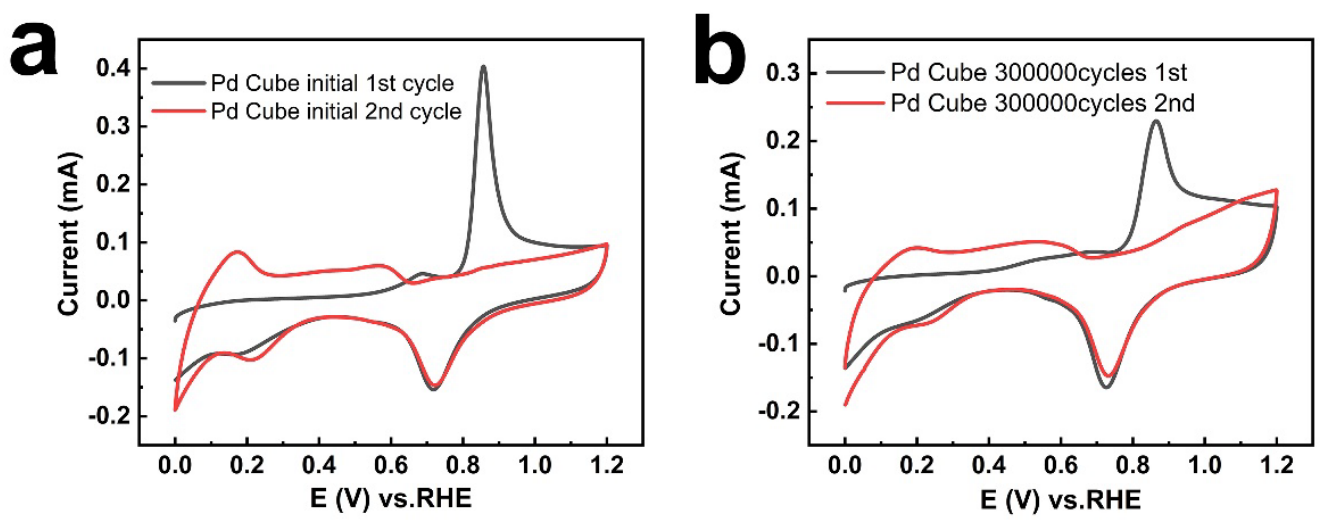

Figure S6. CO stripping curves of $\mathrm{PdCu}$ cube/C (a)before 30000 cycles (b)after 30000 cycles 

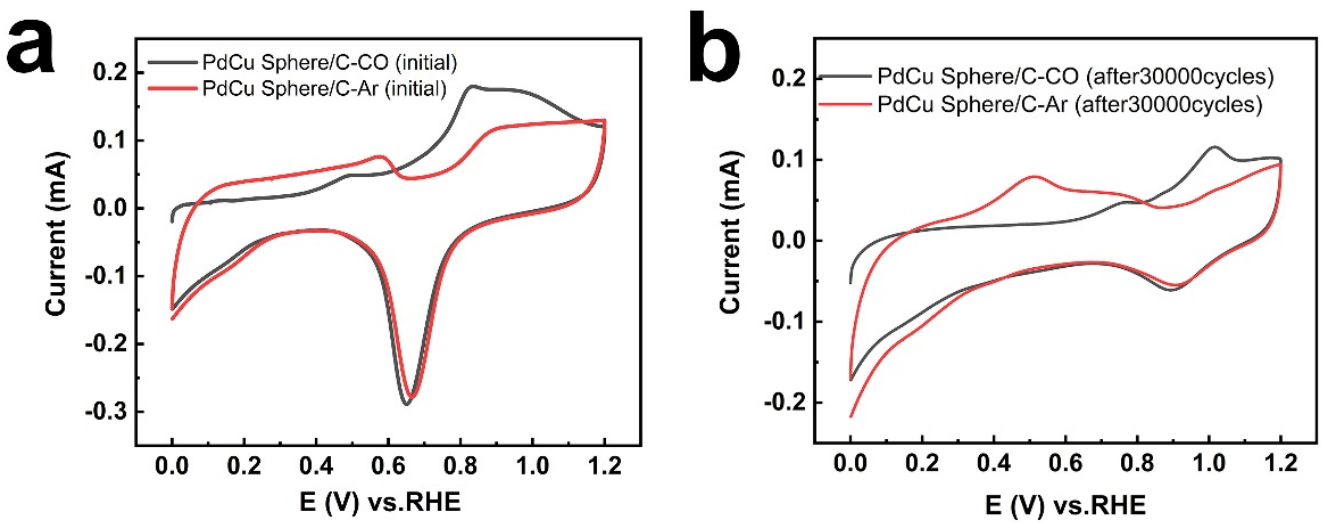

Figure S7. CO stripping curves of $\mathrm{PdCu}$ sphere /C (a)before 30000 cycles (b)after 30000 cycles
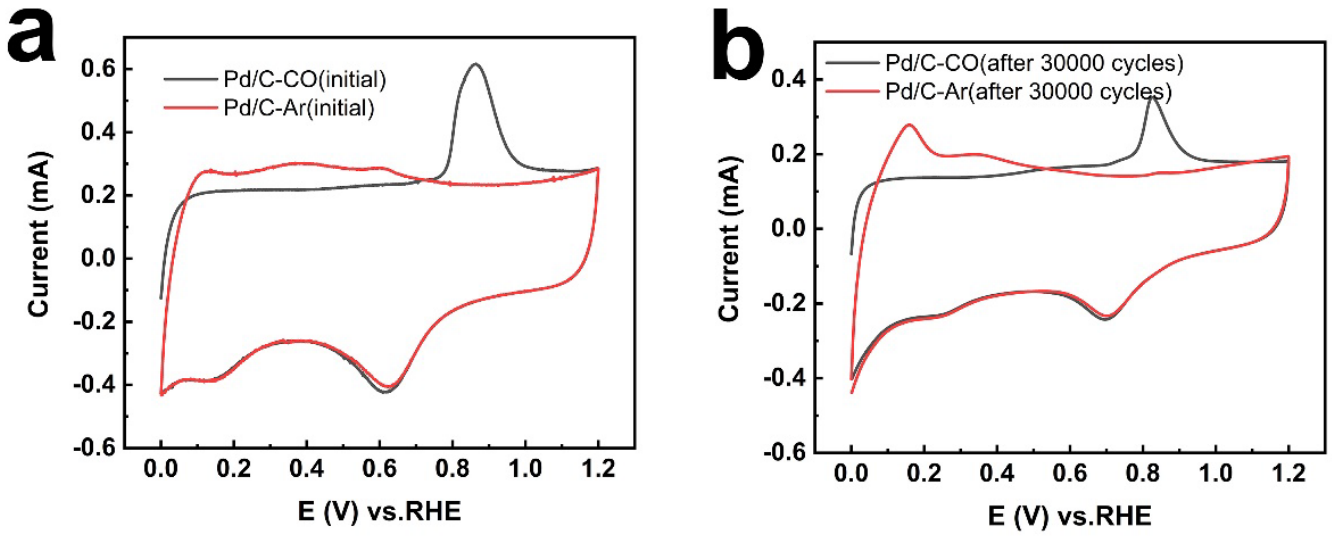

Figure S8. CO stripping curves of the commercial Pd/C (a)before 30000 cycles (b)after 30000 cycles
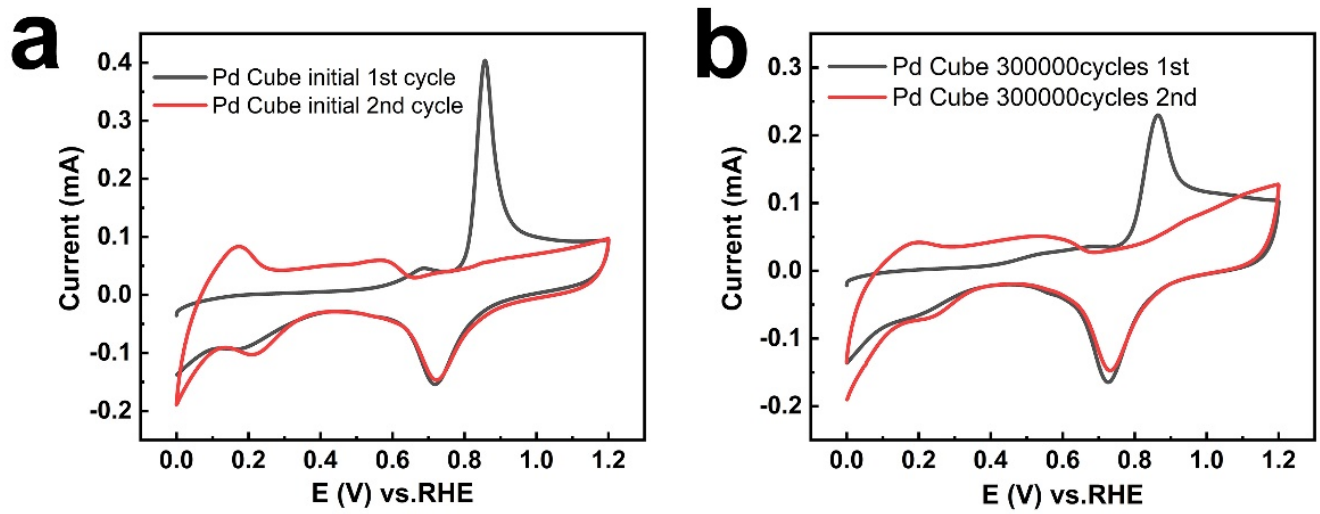

Figure S9. CO stripping curves of the Pd cube/C (a)before 30000 cycles (b)after 30000 cycles 


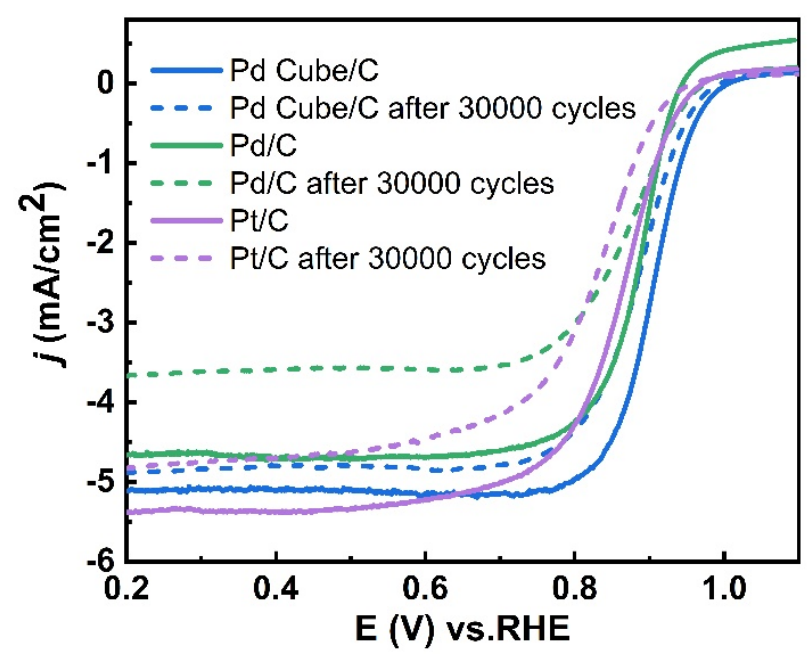

Figure S10. ORR polarization curves of $\mathrm{Pd}$ cube/C, commercial $\mathrm{Pd} / \mathrm{C}$ and $\mathrm{Pt} / \mathrm{C}$ before and after 30000 cycles 


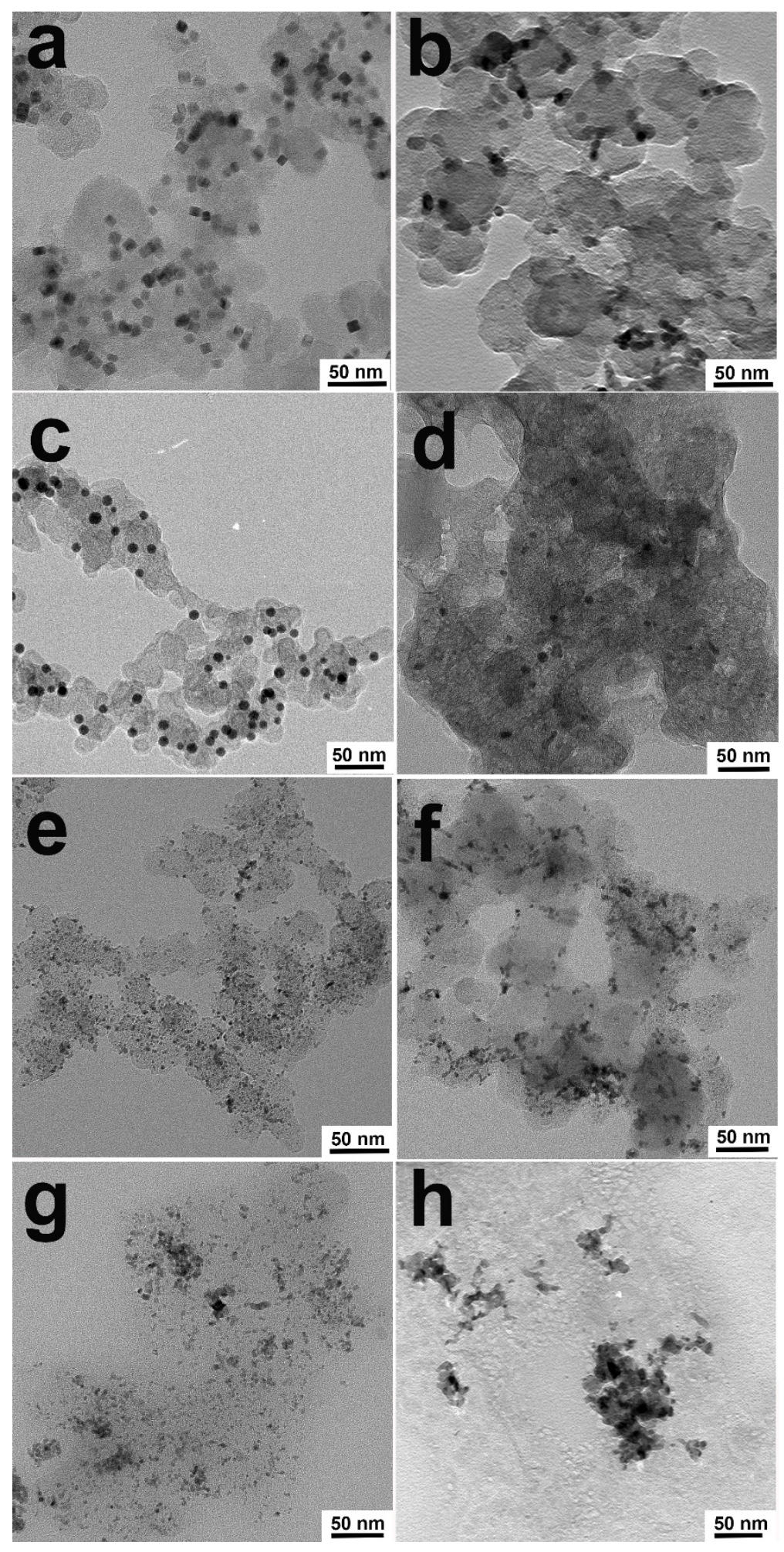

Figure S11. TEM images of $\mathrm{PdCu}$ cube/C (a,b), PdCu sphere/C (c,d), Pt/C (e,f) and $\mathrm{Pd} / \mathrm{C}(\mathrm{g}, \mathrm{h})$ before $(\mathrm{a}, \mathrm{c}, \mathrm{e}, \mathrm{g})$ and after $(\mathrm{b}, \mathrm{d}, \mathrm{f}, \mathrm{h})$ 30,000 electrochemical cycles. 

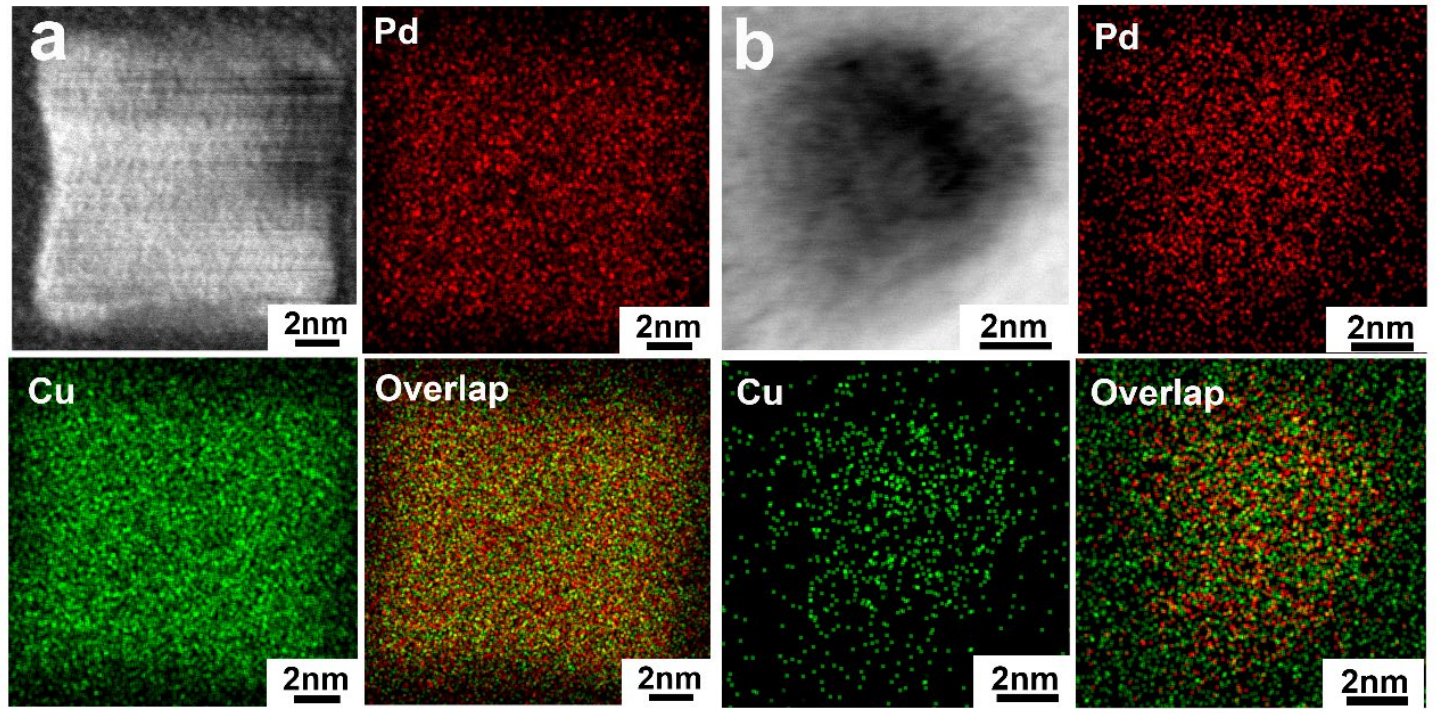

Figure S12. EDS mapping images of $\mathrm{PdCu}$ cube/C (a), PdCu sphere/C (b) after (b,d,f,h) 30,000 electrochemical cycles.

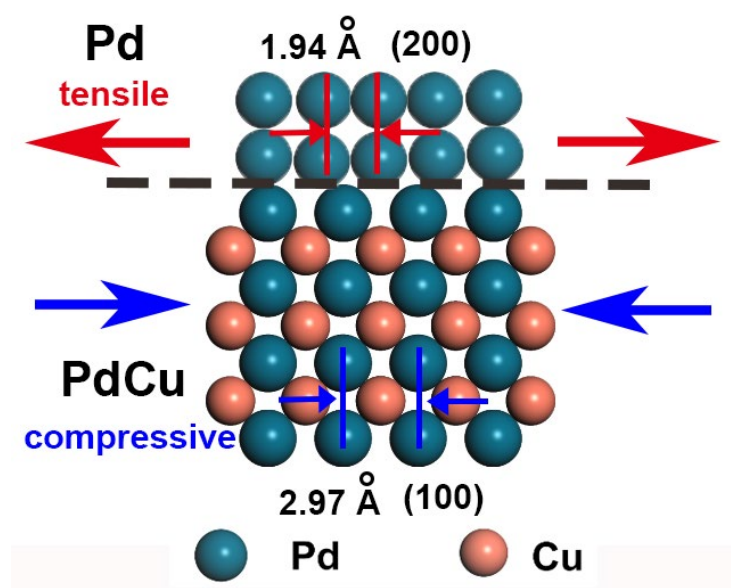

Figure S13. Stress analysis in the surface of PdCu cube (the top are the Pd atoms and inside are $\mathrm{Pd}$ and $\mathrm{Cu}$ atoms, side view) 

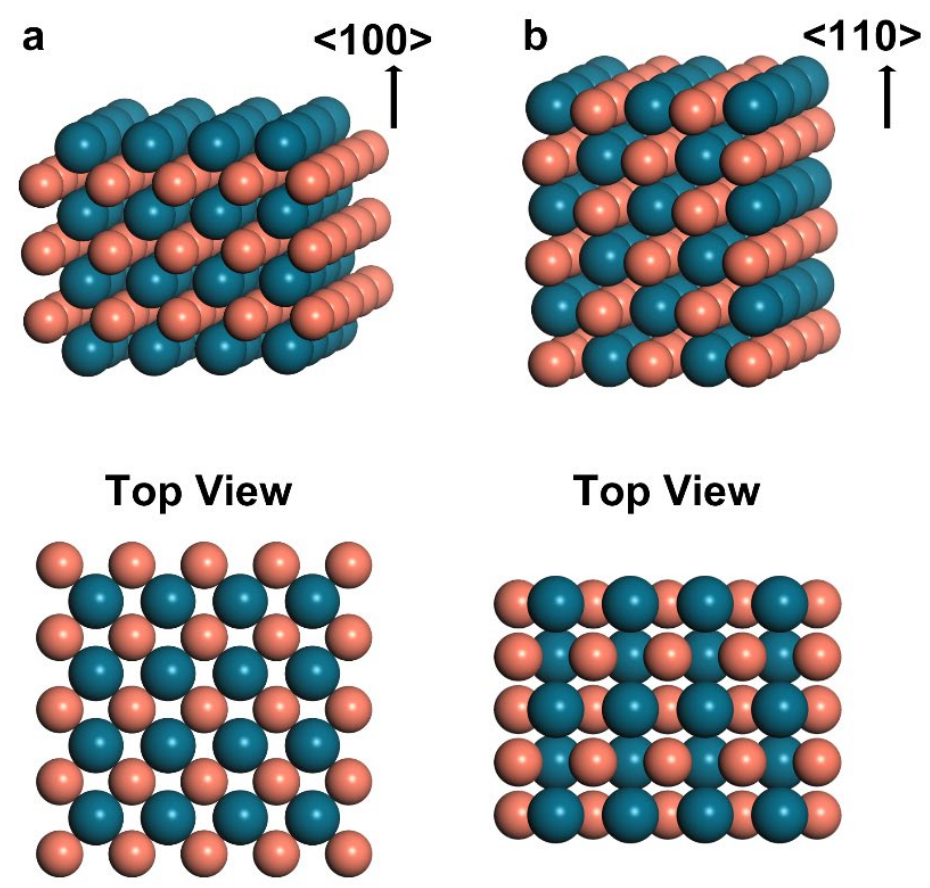

Top View
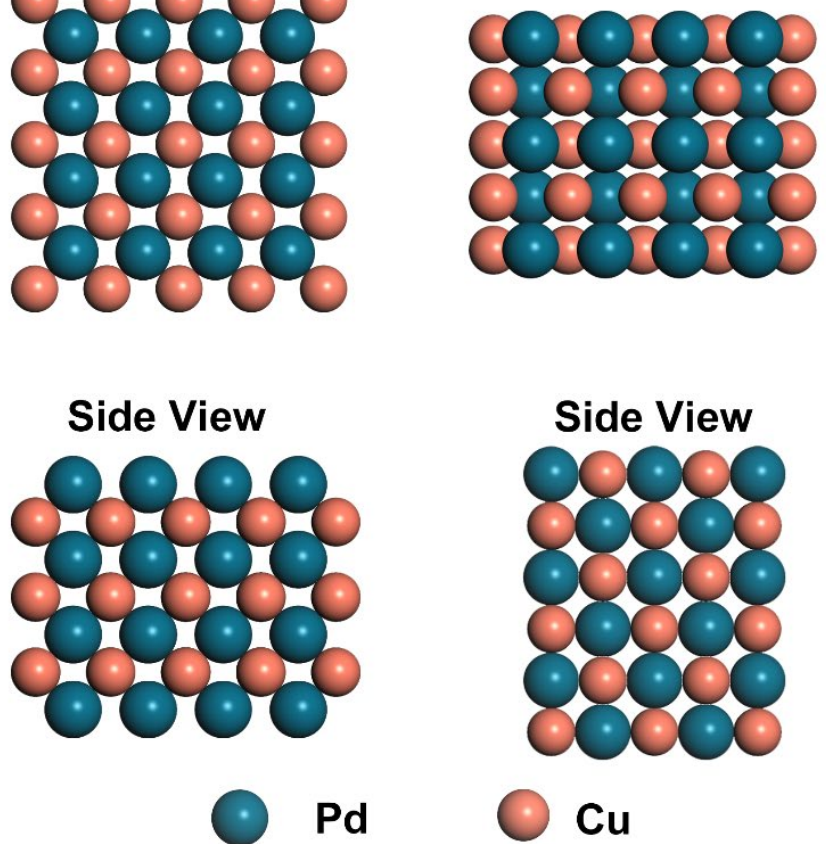

Figure S14. Periodic slab model, top view and side view of (a) PdCu (100) surface, (b) $\mathrm{PdCu}(110)$ surface.

\section{References}

[1] P. E. Blöchl, Phys. Rev. B 1994, 49,16223-16233.

[2] G. Kresse, J. Hafner, Phys. Rev. B 1993, 47,558-561.

[3] G. Kresse, J. Furthmüller, Phys. Rev. B - Condens. Matter Mater. Phys. 1996, 54,11169-11186.

[4] J. P. Perdew, J. A. Chevary, S. H. Vosko, K. A. Jackson, M. R. Pederson, D. J. Singh, C. Fiolhais, Phys. Rev. B 1992, 46,6671-6681.

[5] H. J. Monkhorst, J. D. Pack, Phys. Rev. B 1976, 13,5188-5192

[6] Y. Ma, F. Li, X. Ren, W. Chen, C. Li, P. Tao, C. Song, W. Shang, R. Huang, B. Lv, et al., ACS Appl. Mater. Interfaces 2018, 10,15322-15327.

[7] R. Liu, S. Li, X. Yu, G. Zhang, S. Zhang, J. Yao, B. Keita, L. Nadjo, L. Zhi, Small 2012, 8, 1398-1406. 